\title{
Psycho spiritual characteristics of persons presenting with deliberate self-harm to a suburban hospital in the Western Province of Sri Lanka
}

HPI Jayasekera, KACD Seneviratne, HK Narammalage, AS Embuldeniya, JWS Priyadarshanie, JAF Rosana, MRF Zahriya, SS Williams

\section{Background}

An understanding of the beliefs that underlie the act of deliberate self harm (DSH) is useful. It may help us implement prevention strategies. The objective of our study was to describe the psychological and spiritual attitudes in persons who engaged in DSH.

\section{Method}

A cross-sectional descriptive study was conducted in a sample of 295 consecutive patients aged 15 to 65 years, referred to the psychiatric clinic for assessment following an episode of DSH, at a semi-urban base hospital, in the Western province of Sri Lanka. A selfadministered questionnaire was designed based on Version 4.4 of the Spirituality and Resilience Assessment of the Institute of Contemplative Education, Massachusetts and adapted to suit the Sri Lankan cultural context for data collection. Informed written consent from the participants and ethical approval for the study was obtained.

\section{Results}

Almost all the persons felt that their life was precious to them (89\%). Most felt satisfaction with their life (85\%). A large proportion also had people they could access for emotional support (86\%). Up to $85 \%$ denied it was a cry for help or a means of seeking attention. Interestingly, the majority indicated they never used aggression (80\%), alcohol (76\%) or suicidal acts (64\%) as a coping strategy. More females used religious activities in coping than males $(p=0.016)$ and never used alcohol $(p<0.001)$. There was no significant difference in coping strategies between different age groups.

\section{Conclusion}

Despite having a positive attitude to life the study participants had carried out an act of DSH. The DSH is in dissonance with their core beliefs. DSH prevention strategies should focus on behavioural coping skills that could prevent these impulsive acts.

Key words: suicide, deliberate self-harm, spirituality, attitude, Sri Lanka

SL J Psychiatry 2014; 5(2) 13-18

\section{Introduction}

Deliberate self harm (DSH) is considered a major health problem all over the world (1-3). It is a common problem presenting to the medical services in Sri Lanka too $(4,5)$. Despite a decline in suicide rates since 1995 in Sri Lanka, the hospital admissions related to poisoning, almost always related to DSH, has shown exponential growth (5). The World Health Organisation SUPRE-MISS study reported that in a community sample in Sri Lanka, 0.4$4.2 \%$ had a history of suicide attempts, $1.1-15.6 \%$ had made plans, and 2.6-25.4\% had suicidal ideation (6).

In this context it is important to understand the factors that may be contributing to DSH, so that an effective strategy for prevention of DSH could be implemented.

Most studies from Sri Lanka highlight the fact that in many instances, premeditation is absent and that rates of repetition are low $(3,7)$. It is often a 'once only' impulsive act. This and other evidence points to the fact that the majority of persons with DSH do not have an underlying psychiatric disorder (8). The reported intention to die too was low (9).

Coping styles therefore may have a significant impact on suicidal behaviour. A study conducted in a Japanese adult population on different coping styles and suicidal behaviour found that self-blame was significantly associated with the suicidal behaviour (10). Another study found that adolescents use maladaptive behaviours to cope despite having other methods of coping (11). Social withdrawal, problem solving, and emotional regulation were also found to be used as coping methods (12). Survival-coping beliefs were found to be associated with self-predicted future suicide and other suicidal behaviours (13). Flowers et al reported that women who were able to generate and contemplate reasons for valuing their life had low risk of life-threatening suicidal behaviours, even after controlling for spiritual well-being (14). 
Sri Lanka is home to four major religions, Buddhism, Hinduism, Islam and Christianity, with the majority of its people being active religious adherents. These core beliefs and their contribution to coping styles will no doubt have an impact on suicidal behaviour. But the literature on the psycho-spiritual profile of persons with DSH is scarce.

The objective of our study therefore was to study the psychological and spiritual beliefs related to the act of DSH among persons who have attempted DSH.

\section{Methods}

A cross sectional descriptive study was carried out in Wathupitiwala District Base Hospital, a suburban hospital in the Western province of Sri Lanka. A sample of 266 consecutive Sinhala literate patients aged 15 to 65 years, who were referred to the psychiatric clinic for assessment following treatment of an episode of DSH, were recruited to the study between September 2012 and March 2013. Ethical approval for the study was obtained from the Ethics Committee of the Faculty of Medicine, University of Kelaniya, Sri Lanka.

A self administered questionnaire "The Clinical Record of Deliberate Self-poisoning and Self-harm” was designed for the purpose of gathering data. It had information on demography, reason for the act, method employed and questions on intent. The intent to die was indicated by one of four responses - no intent, mild intent, moderate intent and severe intent. The beliefs tested were based on Version 4.4 of the Spirituality and Resilience Assessment of the Institute of Contemplative Education, Massachusetts and adapted to suit the Sri Lankan cultural context (15). They gave one of three responses - do not agree, do not have an opinion or agree. Following routine assessment at the psychiatry clinic, all eligible partici- pants who gave informed written consent were invited to complete this self-administered questionnaire, by a psychiatric medical officer. Proxy consent was also obtained from an accompanying guardian for those aged below 18 years.

Analysis of quantitative data was done using SPSS version 16. Descriptive statistics were used to summarise results. Comparisons between categorical data were done using nonparametric tests.

\section{Results}

\section{Demography}

The majority (69.9\%) of the population was aged between $16-30$ years and were female (53\%). Almost two thirds (63.9\%) were employed and $46.7 \%$ were involved in unskilled manual labour.

\section{Characteristics of DSH}

The most common method of DSH was medicinal overdose (55.6\%), and paracetamol was the commonest drug used. Prior planning was not seen in $94.4 \%$. At the time of act $39.1 \%$ had moderate thoughts of harming their life and $18.4 \%$ had severe thoughts of harming their life. Only $3 \%$ and $0.8 \%$ had moderate and severe thoughts respectively of harming themselves at the time of examination. Sadness was the most commonly associated feeling at the time of DSH (Figure 1).

Only $6 \%$ of the participants had previous suicidal attempts. Of the participants, 15 (5.6\%) had a history of a mental illness, while 11 were diagnosed with depression and 3 with schizophrenia. Alcohol use was present in $23.3 \%$ and heroin use in $0.4 \%$.

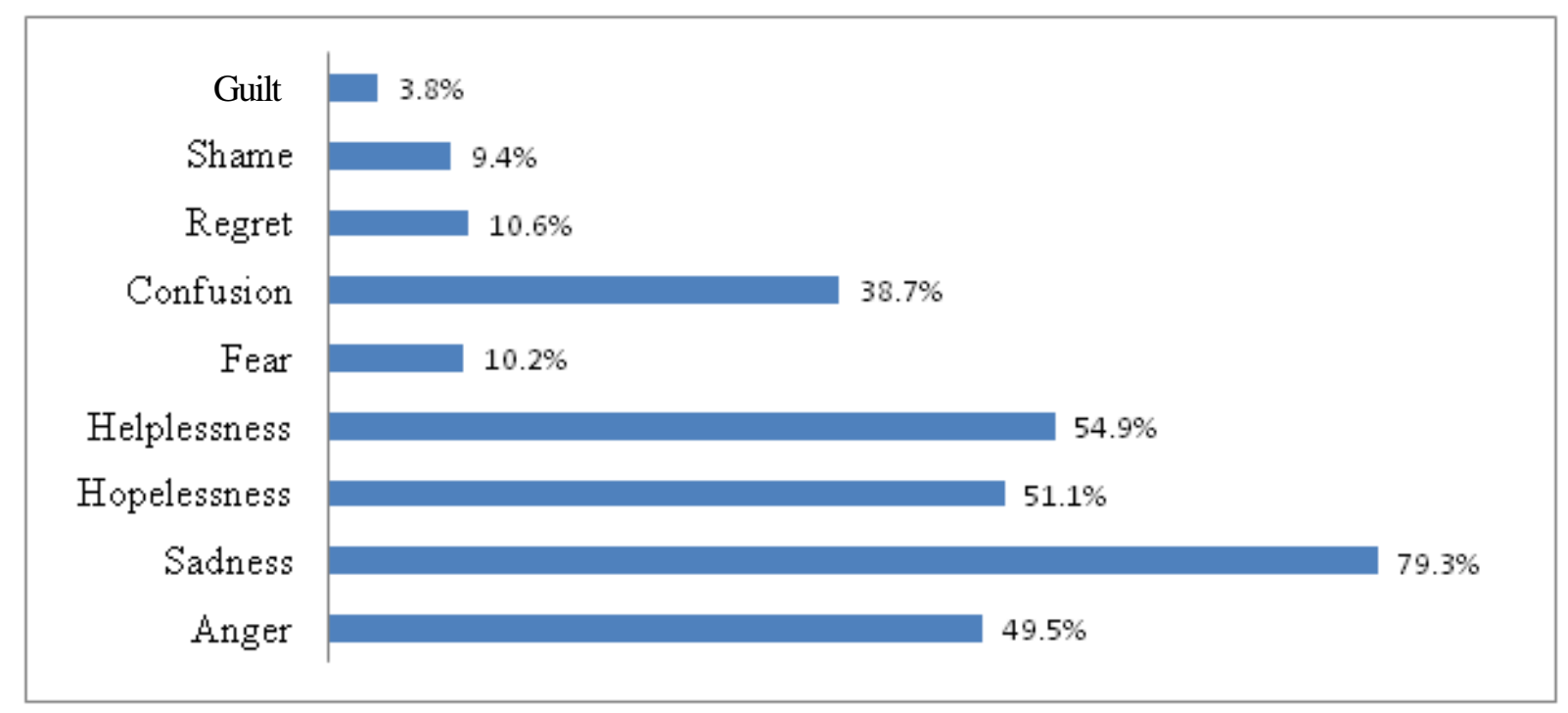

Figure 1. Feelings at the time of DSH 


\section{Coping mechanisms}

The main coping strategies used by the DSH attempters were: trying to solve their problems themselves (85\%); seeking help from others (60\%); expressing their feelings (54\%); and getting involved in religious activities (48\%) (Table 1).
Interestingly, the majority indicated they never used aggression (80\%), alcohol (76\%) or suicidal acts (64\%) as a coping strategy. Compared to males, females used religious activities in coping more often $(p=0.016)$ and never used alcohol $(\mathrm{p}<0.001)$. There was no significant difference in coping strategies between different age groups.

\begin{tabular}{|c|c|c|c|c|c|c|c|}
\hline $\begin{array}{l}\text { Coping } \\
\text { mechanism }\end{array}$ & Sex & $\begin{array}{l}\text { Never } \\
\mathrm{n}(\%)\end{array}$ & $\begin{array}{l}\text { Sometimes } \\
\mathrm{n}(\%)\end{array}$ & $\begin{array}{l}\text { Most of the } \\
\text { time } n(\%)\end{array}$ & $\begin{array}{l}\text { Always } \\
n(\%)\end{array}$ & $\begin{array}{l}\text { Total } \\
\mathrm{n}\end{array}$ & $P$ Value \\
\hline \multirow{2}{*}{$\begin{array}{l}\text { I try to solve the } \\
\text { problem myself }\end{array}$} & Male & $0(0)$ & $17(13.6)$ & $64(51.2)$ & $44(35.2)$ & 125 & \multirow{2}{*}{0.635} \\
\hline & Female & $1(0.7)$ & 21(14.9) & $77(54.6)$ & $42(29.8)$ & 141 & \\
\hline \multirow{2}{*}{$\begin{array}{l}\text { I seek help from } \\
\text { others }\end{array}$} & Male & $12(9.6)$ & $41(32.8)$ & $58(46.4)$ & $14(11.2)$ & 125 & \multirow{2}{*}{0.319} \\
\hline & Female & $6(4.3)$ & $48(34)$ & $66(46.8)$ & $21(14.9)$ & 141 & \\
\hline \multirow{2}{*}{$\begin{array}{l}\text { I express my } \\
\text { feelings }\end{array}$} & Male & $5(4)$ & $56(44.8)$ & $48(38.4)$ & $16(12.8)$ & 125 & \multirow{2}{*}{0.364} \\
\hline & Female & $10(7.1)$ & $52(36.9)$ & $64(45.4)$ & $15(10.6)$ & 141 & \\
\hline \multirow{2}{*}{$\begin{array}{l}\text { I get involved in } \\
\text { activities that } \\
\text { bring me pleasure }\end{array}$} & Male & $12(9.6)$ & $74(59.2)$ & $32(25.6)$ & $7(5.6)$ & 125 & \multirow{2}{*}{0.515} \\
\hline & Female & $22(15.6)$ & $79(56)$ & $34(24.1)$ & $6(4.3)$ & 141 & \\
\hline \multirow{2}{*}{$\begin{array}{l}\text { I get involved in } \\
\text { religious activities }\end{array}$} & Male & $17(13.7)$ & $60(48.4)$ & $40(32.3)$ & $7(5.6)$ & 124 & \multirow{2}{*}{$0.016^{*}$} \\
\hline & Female & $16(11.4)$ & $44(31.4)$ & $66(47.1)$ & $14(10)$ & 140 & \\
\hline \multirow{2}{*}{$\begin{array}{l}\text { I avoid thinking } \\
\text { about the problem }\end{array}$} & Male & $34(27.2)$ & $76(60.8)$ & $12(9.6)$ & $3(2.4)$ & 125 & \multirow{2}{*}{0.672} \\
\hline & Female & $39(27.9)$ & $86(61.4)$ & $9(6.4)$ & $6(4.3)$ & 140 & \\
\hline \multirow[t]{2}{*}{ I consume alcohol } & Male & $67(54)$ & $48(38.7)$ & $7(5.6)$ & $2(1.6)$ & 124 & \multirow{2}{*}{$0.001^{*}$} \\
\hline & Female & 135(95.7) & $2(1.4)$ & $3(2.1)$ & $1(0.7)$ & 141 & \\
\hline \multirow{2}{*}{$\begin{array}{l}\text { I become } \\
\text { aggressive }\end{array}$} & Male & $86(68.8)$ & $34(27.2)$ & $3(2.4)$ & $2(1.6)$ & 125 & \multirow{2}{*}{0.394} \\
\hline & Female & $95(67.4)$ & $40(28.4)$ & $6(4.3)$ & $0(0)$ & & \\
\hline \multirow{2}{*}{$\begin{array}{l}\text { I try to commit } \\
\text { suicide }\end{array}$} & Male & $95(76.6)$ & $26(21)$ & $2(1.6)$ & $1(0.8)$ & 124 & \multirow{2}{*}{0.234} \\
\hline & Female & $119(85.6)$ & 19(13.7) & $1(0.7)$ & $0(0)$ & 139 & \\
\hline
\end{tabular}

$* P<0.05$

\section{Beliefs about DSH}

The majority of the participants were of the view that DSH was a $\sin (81.2 \%)$, and that it denoted a weakness of personality (74.4\%) (Table 2). More than $80 \%$ did not agree with the viewpoint that DSH was a way of seeking attention, a cry for help or the legitimate choice of an individual. There was no significant difference between males and females, with regards to these factors.

\section{Social and spiritual resources}

Almost all the persons felt that their life was precious to them (89\%) (Figure 2). Most felt satisfaction with their life (85\%). A large proportion also had people they could access for emotional support (86\%). A majority also declared an internal locus of control in the form of 'I can stand up for myself if needed' (79\%), 'I have the ability to solve my problems' (79\%) and 'I have the freedom to make my choices” (72\%).

A strong sense of religious coping too was seen with $60 \%$ saying that their religion helped them face their problems; almost $80 \%$ of participants stated that they did not lose faith during times of adversity. Nearly one third spent time in prayer or meditation, and a similar proportion experience inner peace through prayer and meditation. 
Jayasekera, et al

However, negative appraisal of problems too were seen with $62 \%$ indicating they felt negative and hopeless when faced with problems and $66 \%$ indicating they could not maintain a clear mind during times of stress. Of the participants $64 \%$ were sensitive to criticism and $37 \%$ felt isolated from others.

\begin{tabular}{|l|l|l|l|}
\hline Table 2. Beliefs about DSH & Agree (\%) & None (\%) \\
\hline Belief & Disagree (\%) & 81.2 & 11.7 \\
\hline It's a sin & 6.8 & 34.6 & 18.8 \\
\hline A result of mental illness & 46.2 & 74.4 & 12 \\
\hline It is due to weakness of personality & 13.2 & 13.5 & 5.6 \\
\hline It is a legitimate choice & 80.1 & 8.3 & 7.1 \\
\hline It is a cry for help & 83.8 & 7.5 & 6.0 \\
\hline A way of seeking attention & 86.1 & & 7.5 \\
\hline
\end{tabular}

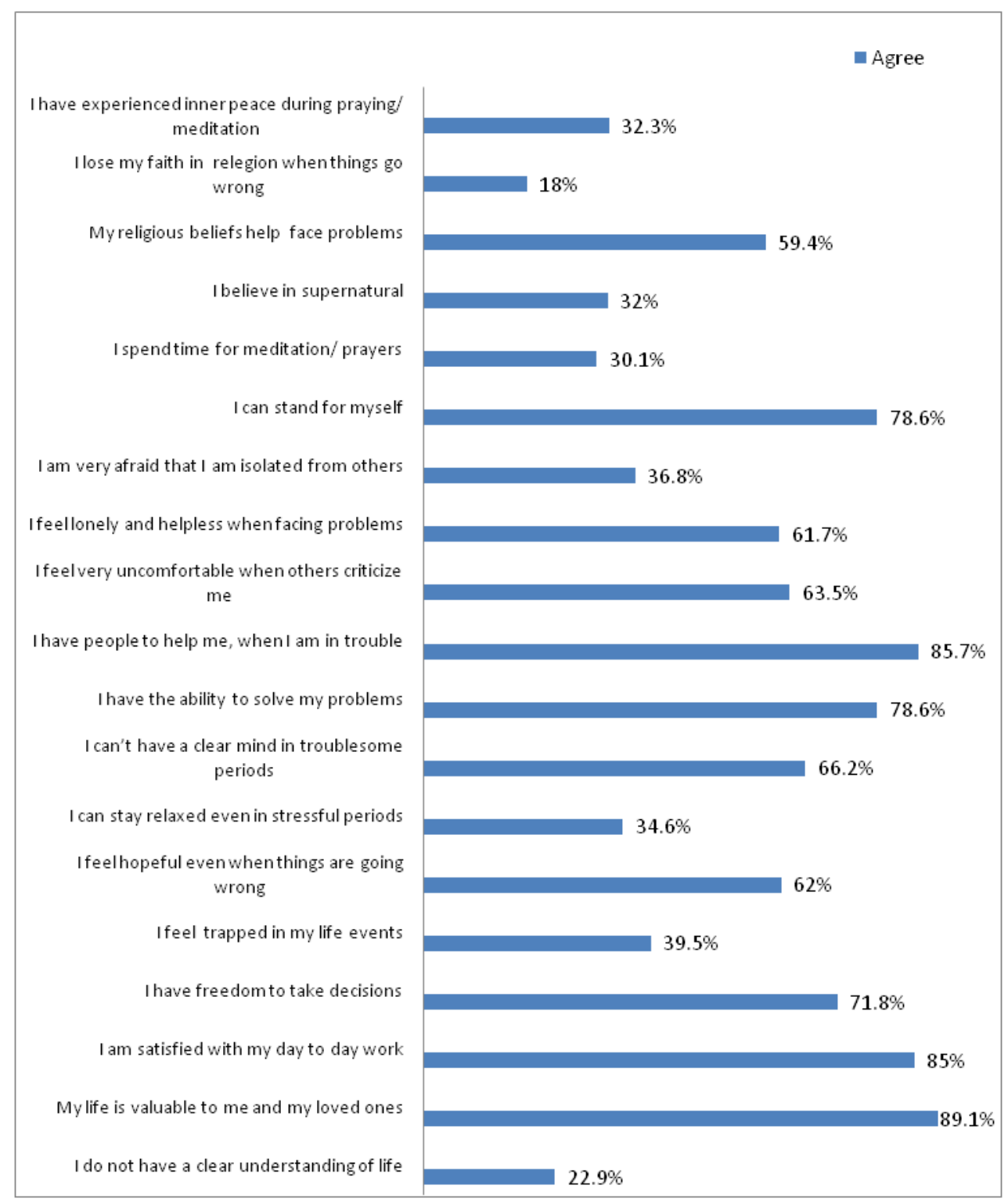

Figure 2. Social and spiritual perceptions indicated by persons with DSH 


\section{Discussion}

This study gives interesting insights in to the beliefs and self-perceptions of those presenting with DSH. The majority valued their life, had a strong sense of responsibility for their actions and felt they had people and resources they could access. They also believed that DSH was a sinful act and that it denoted a weakness of personality. They denied it was a cry for help or attention seeking behaviour.

This withstanding, they engaged in DSH at times of crises. They indicated extreme feelings of sadness, hopelessness, helplessness and anger. This begs the question whether poor impulse control and lack of emotional regulation were at the core of the problem. The underlying schema or world view was not changed or distorted. This is further supported by the finding that even though a majority had a moderate or severe intention of harming their lives at the time of act, only a few continued to have that intention at the time of examination. A majority also had no prior planning.

The majority identified the strengths they have within them, such as an ability to solve their problems, having people to help when in trouble, standing up for themselves when necessary, and being satisfied with their life. Many also acknowledged the role of religion in helping them cope with their problems. Therefore, it appears that they are unable to identify the available resources and alternatives at the time of the DSH. It is not as if they had lost all hope nor did not have access to resources. These findings indicate that they need to develop the ability to tap in to these resources when distressed. Training in this direction is likely to be helpful. These findings will be useful for DSH prevention strategies. It is noteworthy that the DSH population may have different characteristics from the completed suicide population $(1,5)$. Therefore DSH prevention strategies may have to be different from suicide prevention strategies. Often this distinction is not made as both categories are lumped in to the same mould.

The first WHO world suicide report published in 2014 lays emphasis on training gatekeepers and having access to trained counsellors (1). Suicide prevention strategies target vulnerable groups such as those with alcohol and drug issues or mental disorders (1). The wider public health approaches target adolescents and youth in schools and other settings. However, most approaches lay emphasis on early identification and referral of persons with suicidal ideation (1). Most persons with DSH in our population do not fall in to this category. It was not a lack of emotional support that led to DSH in the majority of those we studied. The DSH was an impulsive act, and in many cases the time taken for consideration of the act and the action itself appear to have been a few minutes, as shown in a previous study (16). This is not a realistic window of opportunity for intervention by professional counsellors.

In terms of our findings, the public health approach targeting adolescents and young adults is further supported. The emphasis though should be on improving coping strategies, rather than on identifying suicidal thoughts or behaviours. Acknowledging that anger and sadness are normal emotions and training young people to deal with them positively from a young age is what we should be focussing on.

It can be argued that most of the persons in our study used an emotional coping style as opposed to a cognitive or problem solving one, when sad or angry. Their cognitive appraisal of the act was positive and did not feed in to suicidal behaviour. Their behaviour though appeared to over-ride their inner beliefs.

We need to acknowledge that this study was selfreported and questionnaire based. It did not bring out the qualitative aspects of underlying thoughts and perceptions. The other limitation is that the study is based in a suburban hospital with certain socio-economic and cultural characteristics, perhaps different from other regions. Affluent patients may have accessed private health care and others with serious DSH may have been admitted to larger hospitals. We are also not aware of the baseline religious characteristics of those in the base population, to comment on how it is different from the DSH population.

This withstanding, this is the only study that has looked at the psychological and spiritual beliefs of persons with DSH in Sri Lanka. The findings are useful for planning DSH prevention strategies in the Sri Lankan and Asian context.

\section{Declaration of interest}

None declared

HPI Jayasekera, KACD Seneviratne, JWS Priyadarshanie, JAF Rosana, MRF Zahriya, Psychiatry Unit, Base Hospital, Wathupitiwala

HK Narammalage, AS Embuldeniya, SS Williams, Department of Psychiatry, Faculty of Medicine, University of Kelaniya.

Corresponding author: SS Williams

Email: shehanwil@gmail.com

\section{References}

1. World Health Organization. [homepage on internet] Preventing Suicide - A global imperative. c2014. Available at: http://www.who.int/mental_health/suicide-prevention/ en/ (accessed Oct 2014)

2. Holding TA, Buglass D, Duffy JC, Kreitman N. Parasuicide in Edinburgh- a seven year review. Br J Psychiatry 1977; 130: 534-43.

3. Fleischmann A, Bertolote JM, De Leo D, et al. Characteristics of attempted suicides seen in emergencycare settings of general hospitals in eight low- and middle- 
income countries. Psychological Medicine 2005; 35(10): 1467-74.

4. Eddleston, Michael, Sheriff MHR, Hawton K. Deliberate self harm in Sri Lanka: an overlooked tragedy in the developing world. BMJ 1998; 317(7151): 133-5.

5. De Silva VA, Senanayake SM, Dias P, Hanwella R. From pesticide to medicinal drugs: time series analyses of methods of self-harm in Sri Lanka. Bull World Health Organ 2012; 90(1): 40-6.

6. Bertolote JM, Fleischmann A, De Leo D, et al. Suicide attempts, plans, and ideation in culturally diverse sites: the WHO SUPRE-MISS community survey. Psychological Medicine 2005; 35(10): 1457-65.

7. Rajapakse T, Griffiths KM, Christensen H. Characteristics of non-fatal self-poisoning in Sri Lanka: a systematic review. BMC Public Health 2013; 13: 331.

8. van der Hoek W, Konradsen F. Risk factors for acute pesticide poisoning in Sri Lanka. Trop Med Int Health 2005; 10(6): 589-96.

9. Eddleston M, Ariaratnam CA, Meyer WP, Perera G, Kularatne AM, Attapattu S, Sheriff MH, Warrell DA. Epidemic of self-poisoning with seeds of the yellow oleander tree (Thevetiaperuviana) in northern Sri Lanka. Trop Med Int Health 1999; 4(4): 266-73.

10. Svensson $\mathrm{T}$, Inoue $\mathrm{M}$, Charvat $\mathrm{H}$, et al. Coping behaviors and suicide in the middle-aged and older Japanese general population: the Japan Public Health Center-based Prospective Study. Ann Epidemiol 2014; 24(3): 199-205.

11. Nock MK, Borges G, Bormet EJ, Cha CB, Kessler RC, Lee S. Suicide and suicidal behavior. Epidemiol Rev 2008; 30(1): 133-54.

12. Spirito A, Overholse J, Stark LJ. Common problems and coping strategies II: Findings with adolescent suicide attempters. J Abnorm Child Psychol 1989; 17(2): 213-21.

13. Cole DA. Psychopathology of adolescent suicide: Hopelessness, coping beliefs, and depression. J Abnorm Psychol 1989; 98(3): 248-55.

14. Flowers KC, Walker RL, Thompson MP, KaslowNJ. AssociationsBetween Reasons for Living and Diminished Suicide Intent Among African-American Female Suicide Attempters. J Nerv Ment Dis 2014; 202(8): 569-75.

15. Kass J, Kass L. Manual for the Spirituality and Resilience Assessment Packet. Cambridge, MA: Behavioral Health Education Initiative Monograph, Greenhouse Psychotherapy Associates; 2000.

16. Deisenhammer EA, Ing CM, Strauss R, Kemmler G, Hinterhuber H, Weiss EM. The duration of the suicidal process: how much time is left for intervention between consideration and accomplishment of a suicide attempt? J Clin Psychiatry 2009; 70(1): 19-24. 